\title{
TESES DAS TESES EM CONTABILIDADE NA USP
}

\author{
THESIS OF THESIS IN ACCOUNTING AT USP
}

\section{TESIS DE LAS TESIS EN CONTABILIDAD EN LA USP}

\section{GILBERTO JOSÉ MIRANDA}

Professor Assistente da FACIC/UFU. Graduado em Ciências Contábeis, Especialização em Controladoria e Finanças e Especialização em Docência na Educação Superior, Mestrado em Administração de Empresas (FAGEN/UFU) e Doutorando em Ciências Contábeis (FEA/USP). gilbertojm1@gmail.com
\end{abstract}

\section{RENATO FERREIRA LEITÃO AZEVEDO}

Mestre em Ciências Contábeis (FEAUSP), Bacharelando em Filosofia (FFLCH-USP). É Bacharel em Ciências Contábeis (FEA-USP) e Bacharel em Sistemas de Informação (Universidade Anhembi Morumbi). Atua como Instrutor no MBA Controller e no CEFIN da FIPECAFI e professor da Faculdade Sumaré para os cursos de Teoria da Contabilidade, Introdução a Contabilidade I e Il e Comportamento Organizacional, Doutorando em Human Resource Education, University of Illinois at Urbana-Champaign (UIUC).

renatoflazevedo@gmail.com

\section{GILBERTO DE ANDRADE MARTINS}

Professor Titular do Departamento de Contabilidade e Atuária da FEA/USP. Editor da Revista Contabilidade \& Finanças USP. Pesquisador da FIPECAFI. Ex Coordenador do Curso de Graduação em Contabilidade da FEA/USP. Ex Coordenador do Programa de Pòs-Graduação em Contabilidade e Controladoria da FEA/USP. 


\section{RESUMO}

As Ciências Contábeis, em termos científicos, constituem uma área relativamente jovem, mas com desenvolvimento bastante promissor, se considerado o crescimento experimentado pela pós-graduação stricto sensu nesta década. Os estudos epistemológicos realizados na área apontam melhorias na produção científica nos últimos anos, mas também detectam falhas científicas graves. Diante desse contexto, o presente estudo tem como objetivo verificar se as Teses de Doutorado em Contabilidade, de fato, respondem a um problema de pesquisa, elencando variáveis relacionadas e se testam essas variáveis empiricamente. O objeto de estudo é composto pelas teses de Doutorado em Ciências Contábeis defendidas no Brasil no período de 2004 a 2008, realizado por meio de análise de conteúdo. Os resultados encontrados mostram que predominam os estudos teórico-empíricos (84\%) com ênfase na modalidade quase-experimento (58\%). As pesquisas, em sua totalidade, enunciam os problemas de pesquisa, mas ainda apresentam questões de valor na elaboração dos problemas (8\%). As hipóteses de estudo foram enunciadas na maioria dos trabalhos (62\%); desses, 38\% apresentavam relação causal acidental e $24 \%$, relação de causalidade necessária. Finalmente, foi constado que alguns autores (20\%) começaram a enunciar claramente as teses das pesquisas realizadas. Todavia, esse fato foi observado somente a partir de 2007.

Palavras-chave: Tese; Doutorado; Epistemologia; Contabilidade.

\section{ABSTRACT}

Accounting Sciences in scientific terms is a relatively young area, but with a very promising development when considering the growth experienced by stricto sensu post-graduate studies in this decade. The epistemological studies conducted in the area indicate improvements in scientific production in recent years, but also detect serious scientific flaws. Given this context, this study aims to ascertain whether the Doctoral Thesis in Accounting really answer to a research problem, listing related variables and whether they test these variables empirically. The object of study comprises doctoral theses in Accounting Sciences defended in Brazil between 2004 to 2008, performed through the content analysis. The results found show that the theoretical-empirical studies are predominant $(84 \%)$ with emphasis on quasiexperimental modality (58\%). The total researches set out research problems, but still have questions of value in the elaboration of the problems (8\%). The study hypotheses were stated in most works (62\%); of these, $38 \%$ showed accidental causal relationship and $24 \%$, the required causal relationship. Finally, it was verified that some authors $(20 \%)$ began to clearly state the thesis of the researches conducted. However, this was observed only from 2007. 


\section{repec}

Keywords: Thesis; Doctorate; Epistomology; Accounting.

\section{RESUMEN}

Las Ciencias Contables, en términos científicos, constituyen un área relativamente joven, pero con un desarrollo bastante animador si se considera el crecimiento experimentado por el pos grado stricto sensu en esta década. Los estudios epistemológicos llevados a cabo en el área apuntan hacia mejoras en la producción científica en los últimos años, pero también detectan fallas científicas graves. Ante este contexto, el presente estudio tiene como objetivo verificar si las Tesis de Doctorado en Contabilidad efectivamente responden un problema de investigación, incluyendo variables relacionadas; luego se testan estas variables empíricamente. El objeto de estudio está compuesto por las tesis de doctorado en Ciencias Contables defendidas en Brasil en el periodo de 2004 a 2008, llevado a cabo a través de análisis de contenido. Los resultados encontrados demuestran que predominan los estudios teórico-empíricos (el 84\%), con énfasis en la modalidad casi experimento (el $58 \%$ ). Las investigaciones, en su totalidad, enuncian los problemas de investigación, pero todavía presentan cuestiones de valor en la elaboración de los problemas (el $8 \%$ ). Las hipótesis de estudio han sido enunciadas en la mayoría de los trabajos (el $62 \%$ ); de ésos, el $38 \%$ presentaban relación causal accidental, y el $24 \%$, una relación de causalidad necesaria. Finalmente, se ha constatado que algunos autores (el 20\%) han comenzado a enunciar claramente las tesis de las investigaciones llevadas a cabo. Sin embargo, ese hecho se ha observado solamente a partir de 2007.

Palabras clave: Tesis; Doctorado; Epistemología; Contabilidad.

\section{INTRODUÇÃO}

O crescimento experimentado nesta década pela pós-graduação em Ciências Contábeis demonstra a importância de estudos de natureza epistemológica no campo das Ciências Contábeis. No ano 2000, eram apenas seis programas de mestrado e um de doutorado em Ciências Contábeis aprovados pela Capes. No final de 2009, já eram dezoito programas de mestrado e quatro programas de doutorado. Um crescimento de $200 \%$ no mestrado, e $300 \%$ no doutorado. Portanto, é de se esperar que a produção científica da área cresça de forma proporcional, mas isso não significa que a cientificidade de tais pesquisas esteja automaticamente alcançada. Segundo Njoku, Van Der Heijden e Inanga (2010, p. 59), na academia, o axioma geral é "publicar ou perecer", pois a produtividade da pesquisa é usada para discriminar entre alto e baixo desempenho. $O$ pressuposto implícito é que um membro do corpo docente, que publica muito seja mais valioso(a) para a comunidade acadêmica do que aquele que não publica com frequência. Assim como o lucro contábil é usado para indicar o sucesso na vida empresarial, as publicações reconhecidas são utilizadas como o principal indicador de qualidade acadêmica. 
Embora os estudos realizados por Theóphilo (2004) e as pesquisas empreendidas por Martins (2002; 2007) e Martins e Theóphilo (2007) apontem para uma melhoria na qualidade científica dos trabalhos ao longo do tempo, é extremamente importante empreender novos estudos a fim de acompanhar, analisar, discutir e debater a produção científica no campo das Ciências Contábeis, para alcançar patamares de maior cientificidade e qualidade acadêmica, pois, de acordo com Ruff et al. (2009, p. 36), a missão das universidades é criar e disseminar o conhecimento. Por isso, universidades e faculdades exigem professores academicamente qualificados, para que possam produzir pesquisas relevantes em suas disciplinas e tornem os estudantes pesquisadores de alta qualidade.

O objeto deste estudo é composto pelas teses de doutorado em Ciências Contábeis defendidas no Brasil no período de 2004 a 2008. O recorte exclusivo nos programas de pós-graduação stricto sensu de doutorado justifica-se em função dos objetivos da pesquisa, que estão pautados na análise das teses e hipóteses apresentadas pelos doutorandos em Ciências Contábeis quando de suas defesas de teses.

No período analisado, existiam três programas de doutorado acadêmico em Ciências Contábeis autorizados pela Capes no Brasil, eram eles: Universidade de São Paulo (USP), Universidade de Brasília (UnB) e Universidade Regional de Blumenau (FURB). No entanto, os dois últimos, por se tratarem de programas novos, não apresentaram concluintes no período coberto pela pesquisa e foram, por conseguinte, desconsiderados para fins amostrais desta.

Considerando a importância da obtenção de conhecimento sistematizado sobre o estágio de desenvolvimento da produção científica no campo da Contabilidade no Brasil, o presente estudo, por meio de uma análise de conteúdo, tem como objetivo geral verificar se as Teses de Doutorado em Contabilidade, de fato, respondem a um problema de pesquisa, elencando variáveis relacionadas e se testam essas variáveis empiricamente. Para tanto, são levantadas e analisadas criticamente as hipóteses e teses observadas na produção científica objeto de estudo e identificadas as inter-relações lógicas entre esses elementos.

Além desta introdução, o estudo contempla a plataforma teórica, em que são discutidos os conceitos atinentes ao problema de pesquisa, hipóteses e teses em suas perspectivas filosóficas e teóricas, e uma seção em que são apresentados estudos anteriores sobre o tema. Na terceira seção, é apresentada a trajetória metodológica e, na quarta, são descritos os resultados encontrados. Na sequência, estão as considerações finais e as referências.

\section{PLATAFORMA TEÓRICA}

\subsection{Assunto, Tema e Problema}

Uma pesquisa científica inicia-se com a escolha de um assunto-tema-problema e para esta missão não se tem uma regra básica para ser atendida. No entanto, o tema deve 


\section{repc}

obedecer, ao mesmo tempo, aos princípios da importância, da originalidade e da viabilidade, para que seja categorizado como pesquisa científica.

Nesse sentido, Castro (2006) salienta que a pesquisa é, de fato, científica quando: (1) for ligada a uma questão que afeta um segmento substancial da sociedade ou se vincula com uma questão teórica que merece atenção (importância); (2) quando possui a capacidade de surpreender, de trazer elementos novos, de possibilitar novos entendimentos em relação aos fenômenos observados (originalidade); e (3) quando é passível de observação em relação ao aparato teórico e técnico, às condições de prazo, custo e competências dos pesquisadores (viabilidade).

Para Bunge (1991), o que diferencia a ciência da pseudociência é a presença dos fatores: (a) Inteligibilidade: em que é importante saber se o ponto de vista está claro ou obscuro, e se pode ser elucidado ou formalizado; (b) coerência: em que é importante que os pressupostos não apresentem contradições lógicas; (c) sistemicidade: é a visão de que a pesquisa é parte de um conhecimento maior e nele se apoia; (d) literalidade: a noção da ciência é buscar uma objetividade, evitando metáforas e analogias; (e) testabilidade: busca-se a verificação do ponto de vista conceitual, ou de forma empírica, ou em que o conhecimento até o estágio encontrado se mostra invulnerável à crítica e à experiência; (f) suporte empírico: por decorrência, a visão de que se pode ser testado, os resultados devem ser favoráveis ou desfavoráveis ao ponto teórico, mas não inconclusivos; (g) consistência externa: a visão de que é compatível com o conjunto de conhecimentos dos outros campos da pesquisa científica e do saber; (h) originalidade: busca resolver um problema existente; (i) poder heurístico: é capaz de levantar ainda outros novos problemas de investigação interessantes; (j) solidez filosófica: é visão compatível com a filosofia subjacente à investigação científica.

Para Martins e Theóphilo (2007, p. 5), a primeira escolha na definição da pesquisa se dá no nível do assunto, dentro de um âmbito abrangente do conhecimento (ex: Auditoria). Escolhido o campo e o assunto, o segundo passo se dá na escolha do tema de estudo, que é uma delimitação que objetiva evitar os enfoques genéricos ou muito abrangentes (ex: papel do auditor nas organizações públicas). Em seguida, o tema deverá ser problematizado, ou seja, formulado com clareza e distinção, podendo ser expresso em forma interrogativa, buscando o relacionamento entre duas ou mais variáveis.

Martins e Theóphilo (2007, p.7) ressaltam que dois extremos devem ser evitados: a escolha de temas com muitos estudos e a escolha de temas extremamente inéditos, pois o primeiro impõe o risco da repetição e da falta de originalidade, enquanto o segundo, o risco das especulações. Caso a opção seja por um tema muito explorado, o pesquisador precisará ser criativo de forma a compor resultados não previsíveis e, caso a opção seja por um tema muito inovador, o pesquisador precisará fazer reflexões cuidadosas sobre suas potencialidades e condições. De modo geral, o pesquisador deverá, já nessa primeira etapa do processo de pesquisa, responder, com clareza e precisão, às questões: "O que fazer?" 


\section{repec}

e "Por que fazer?". Da resposta a essas questões, o pesquisador caracteriza o objeto de pesquisa, os antecedentes e a relevância do que pretende desenvolver, pois os problemas de pesquisa são dinâmicos, sendo, portanto, passíveis de modificação ao longo da condução do processo de pesquisa.

De acordo com Kerlinger (2007), assim como nos problemas usuais cotidianos, os problemas de pesquisa também são resolvidos por um processo que se inicia na busca por soluções alternativas e meios diferentes de se chegar ao núcleo deste problema. Ocorre que os problemas que não são propriamente científicos são considerados problemas de valor ou de "engenharia" e apresentam a diferença básica de não poderem ser comprovados em testes empíricos. As questões de "engenharia" são respondidas pelo "como fazer alguma coisa", e as questões de valor são respondidas pela "decisão tomada de qual de duas ou mais coisas é melhor ou pior que outra", ou "se alguma coisa sob consideração é boa, má, desejável, indesejável, ou moralmente certa ou errada". A ciência não pode responder a questões de "engenharia" ou de valor, pois não pode testar tais proposições e mostrar sua correção ou incorreção. É importante não confundir aqui os problemas de "engenharia", que dizem respeito ao "como fazer alguma coisa" com os problemas científicos atinentes ao campo das engenharias.

As questões científicas contêm proposições testáveis com variáveis que podem ser medidas ou manipuladas ou que implicam tais medições e manipulações de variáveis. Park (2000) salienta que alguns dos problemas do pensamento pseudocientífico é que estes são repletos de anedotas revestidas de linguagem científica, usam técnicas de correlação sem respeitar o nexo de causalidade, baseiam-se em coincidências e descrevem o como fazer alguma coisa, sem a preocupação de explicar o fenômeno de fato.

Em sentido geral, um problema é uma questão que mostra uma situação necessitada de discussão, investigação, decisão ou solução. No entanto, esta definição geral carrega um significado que é insuficiente e insatisfatório para as finalidades científicas, ainda que seja fácil de ser compreendida no senso comum. No plano das ciências, essa definição poderia ser recolocada como: "Um problema é uma questão que pergunta como as variáveis estão relacionadas".

Para Kerlinger (2007, p. 36), "um problema de pesquisa científica em primeiro lugar é uma questão, uma sentença interrogativa. Segundo, uma questão que geralmente pergunta alguma coisa a respeito das relações entre fenômenos ou variáveis." Para Martins e Theóphilo (2007, p.6), a escolha do assunto-tema-problema pode ser facilitada pela leitura de livros, revistas técnicas, jornais, anais de congressos, dissertações e teses, periódicos, entre outras boas fontes. A escolha de temas vinculados com a atuação profissional do pesquisador também pode tornar o trabalho mais interessante e eficiente, dado que oferece melhores condições e conhecimentos prévios na condução da pesquisa.

Martins e Theóphilo (2007, p.6) enfatizam que a internet pode também facilitar o acesso a diversas bases de dados, de bibliotecas, congressos e periódicos nacionais e in- 
ternacionais. É recomendável também o diálogo com professores e colegas, uma vez que ideias podem surgir de conversas informais e, muitas vezes, os professores já possuem alguma pesquisa em desenvolvimento. A observação direta do comportamento dos fenômenos em alguns casos também pode servir de inspiração e estímulo para pesquisas, bem como da confrontação de ideias do chamado senso comum. Muitos modelos e teorias aplicados em uma determinada área do saber podem ser analogamente estudadas em outras áreas, originando vários campos fecundos e transdisciplinares.

Assim, a definição do problema de pesquisa assume centralidade no planejamento da investigação, pois, de acordo com Theóphilo (2004), o problema de pesquisa é um indicador da robustez, ou não, da proposta do estudo, e sua definição criteriosa, um importante quesito para a consistência lógica do trabalho.

\subsection{Hipóteses}

Abbagnano (2007, p. 582) define o termo "hipótese" como sendo "um enunciado (ou conjunto de enunciados) que só pode ser comprovado, examinado e verificado indiretamente, através das suas consequências." Para o autor, os atributos fundamentais da hipótese são: não apresenta garantias de veracidade e nem a possibilidade de verificação direta. Assim, "uma premissa evidente não é uma hipótese, mas no sentido clássico do termo, um axioma", da mesma forma, "um enunciado verificável é uma lei ou uma proposição empírica, não uma hipótese”. Desse modo, uma hipótese pode ser verdadeira, mas tal veracidade somente será conhecida após sua verificação.

Ainda de acordo com Abbagnano (2007, p. 582), é nesse sentido que Aristóteles entendia a hipótese, ou seja, sua determinação ocorre "como premissa de grau ou qualidade inferior, isenta da necessidade própria das premissas autênticas". Em Platão, diferentemente, afirma o autor, "as premissas devem ser escolhidas com base no juízo comparativo, que se orienta para aquela que é 'a mais forte' ou 'a melhor' entre elas”.

Avançando um pouco mais na linha do tempo, Abbagnano (2007, p. 582) afirma que nos séculos XVII e XVIII, o termo hipótese foi usado frequentemente com o significado de "explicação causal dos fenômenos". Como ilustração de tal acepção, o autor apresenta um trecho da clássica obra de Newton, Princípios.

[...] até agora explicamos os fenômenos do Céu e do nosso mar por intermédio do poder da gravidade, mas não atribuímos nenhuma causa a este poder. É certo que deve proceder de uma causa que penetre até os próprios centros do sol e dos planetas... Mas até agora não pude descobrir as causas dessa propriedade da gravidade a partir dos fenômenos, e não forjo hipóteses. Pois o que não está deduzido dos fenômenos há que chamá-lo hipótese; e as hipóteses, sejam metafísicas ou mesmo físicas, sejam de qualidades ocultas ou mesmo mecânicas, não têm lugar na filosofia experimental. 


\section{repc}

Nesta filosofia as proposições particulares inferem-se dos fenômenos e logo se tornam gerais por indução.

Para Abbagnano (2007, p. 583), “a renúncia de Newton, às hipóteses nada mais é que a renúncia à explicação em favor da descrição". Aliás, tem-se discutido bastante o sentido dessa passagem famosa e, sem entrar em pormenores, pode afirmar-se que, em última análise, as hipóteses inadmissíveis na ciência são as de caráter metafísico.

Mora (2001, p. 334), ao discutir o significado de hipótese, afirma que "na atualidade, preocupam, sobretudo questões como as da acepção, ou acepções, de 'hipótese'; a natureza das inferências hipotéticas ou do chamado 'raciocínio hipotético', os modos de verificar, contrastar ou falsear hipóteses; e as possíveis categorias de hipóteses".

Para Mora (2001, p. 334),

(...) uma hipótese expressa-se mediante um condicional acompanhado de um ou vários enunciados, que certificam se a consequência (ou consequências) do condicional é ou não verdadeira, e de uma conclusão. Se se pode provar que o consequente do condicional não é verdadeiro, o antecedente tampouco é verdadeiro. Se se pode provar que o consequente é verdadeiro, não é dedutivamente válida a verdade do antecedente, mas a repetida confirmação da verdade do consequente não é indiferente ao conhecimento que se possa ter do antecedente, ainda que não seja dedutivamente concludente.

No entendimento de Mora (2001, p. 335), faz parte do raciocínio dedutivo não saber se uma ou mais premissas são verdadeiras, uma vez que a constatação de tal veracidade é exatamente o que se pretende averiguar. Nesse sentido, pode ocorrer que "uma ou mais premissas neguem uma determinada opinião ou crença com o objetivo de averiguar se esta é falsa e se sua negação é verdadeira". Também pode ocorrer que "se considere a premissa ou premissas como falsas para determinar se a sua negação é verdadeira."

Kerlinger (2007, p. 38) entende que "uma hipótese é um enunciado conjetural das relações entre duas ou mais variáveis", ou seja, são sentenças declarativas que relacionam, de alguma forma, variáveis com outras variáveis. De forma semelhante aos problemas, as hipóteses implicam a testagem das relações enunciadas. A diferença é que geralmente as hipóteses são mais específicas do que os problemas, pois estão mais próximas das operações de teste e pesquisa. "Elas possuem o objetivo profundo e altamente significativo de tirar o homem de si mesmo." (KERLINGER, 2007, p. 39). É na correta formulação e no uso adequado que as hipóteses capacitam o homem a testar aspectos da realidade com um mínimo de distorção causada pelas predileções.

Dessa forma, as hipóteses se constituem como parte da metodologia da ciência associada ao critério de objetividade. Ainda de acordo com Kerlinger (2007, p. 40), as hi- 
póteses são uma "ferramenta poderosa para o avanço do conhecimento porque, embora formuladas pelo homem, podem ser testadas e mostradas como provavelmente corretas e incorretas à parte dos valores e crenças desses homens". As hipóteses ainda apresentam a virtude de poderem ser frequentemente deduzidas de uma teoria. Qualquer teoria de importância conterá um número de implicações empíricas que podem ser dela deduzidas.

Para Vergara (2000, p. 28), hipóteses ou suposições são antecipações da resposta ao problema. Se este é formulado sob a forma de pergunta, a hipótese, ou a suposição, o são sob a forma de uma afirmação. A investigação é realizada de modo que se possa confirmar ou, ao contrário, refutar as hipóteses, ou as suposições. Nesse sentido, Kerlinger (2007) afirma que para serem consideradas cientificamente úteis, as hipóteses precisam ser testáveis ou, no mínimo, conter implicações para teste. Para usar um constructo no teste de uma hipótese, devem-se deduzir, pelo menos até certo ponto, as implicações empíricas ou o significado do constructo.

Dessa forma, as hipóteses, enquanto verdades provisórias estabelecem relações entre variáveis na busca de explicações para a realidade investigada. Para Matallo Júnior (1998), tais relações implicam o conceito de causalidade e podem ser estabelecidas em, pelo menos, três níveis: a) relação acidental entre eventos diferentes. Causalidade própria das explicações do senso comum. Não há a preocupação de formular uma lei invariante que possa ser útil na explicação de outros eventos similares. Por isso, esse tipo de explicação está fora da ciência; b) relação invariante e necessária entre eventos diferentes. A ideia que aparece como principal é a ocorrência de eventos sucessivos no tempo e de que tal sucessão tem caráter necessário, isto é, dado certo evento A, ocorre sempre outro, o B; c) relação invariante, necessária e determinada entre eventos diferentes. Nesse tipo de relação, está a verdadeira explicação científica. A relação pode ser não apenas estipulada, mas também determinada, isto é, pode-se dizer o "como", o "o quando" e o "quanto" da relação. Essas relações são encontradas, normalmente, nas ciências naturais.

\subsection{Tese}

Abbagnano (2007, p. 1139) aponta que o termo "tese" deriva dos textos lógicos de Aristóteles, nos quais se encontra com dois significados principais: (1) "para designar o que o interlocutor põe no início de uma dissertação como assunção sua" e; (2) "para designar uma proposição assumida como princípio". De acordo com o autor, esses dois significados conservaram-se na tradição filosófica. O primeiro encontra-se já em Platão, na sua obra A República, e o segundo, na tradição relatada por Diógenes Laércio. Protágoras teria sido o primeiro a mostrar como apoiar uma tese em argumentos. A segunda acepção foi a que prevaleceu entre na terminologia dos lógicos medievais e dos matemáticos. Complementa Runes (1942, p. 317), salientando que, na lógica aristotélica, a tese é uma proposição usada como premissa para um silogismo, distinta de um axioma por necessitar de uma evidência 


\section{repec}

e não ser intrinsecamente suficiente, ou ainda, uma proposição contrária à opinião pública capaz de ser suportada pela razão.

Para Castro (2006), a tese é a teoria preliminar que será desenvolvida para responder ao problema. É nesse sentido que Julia (1969) apresenta o entendimento de que o termo "tese" pode ser definido como afirmação teórica, ou seja, apresenta-se em geral como uma verdade parcial, cujo contrário é também verdadeiro (“antítese"): a verdade se destaca então por meio de uma "síntese" das duas afirmações, tal é o movimento "dialético" de qualquer pensamento que se forma e desenvolve. Para a autora, do ponto de vista dos títulos universitários, uma tese é uma obra feita com o objetivo de se obter o grau de Doutor.

Martins e Theóphilo (2007), no horizonte das publicações em Contabilidade, também destacam dois sentidos principais para o termo "tese": i) identificar uma proposição formulada com o intuito de ser defendida em público; ii) designar a publicação que contém uma tese. A primeira definição está relacionada à origem histórica da tese. Segundo Eco (1992), a "defesa de tese" representava o momento culminante de quem aspirava ao título de doctor, equivalente ao de "douto" ou "sábio". Sua prática traduz a concreção ou a institucionalização do método filosófico da época: a disputatio (sucessor do maiêutico socrático e do dialético platônico). Cabia ao candidato defender a tese contra as opiniões contrárias ou objeções de seus examinadores (antítese). Nesse sentido, pode-se dizer que a tese seria uma afirmação ou situação inicialmente dada e "defendida".

A segunda definição de tese estabelecida por Martins e Theóphilo (2007) se refere ao trabalho científico propriamente dito, necessário, na atualidade, para a obtenção do grau de "doutor". Nesse sentido, a tese se reveste de algumas características fundamentais: (a) demonstração, por parte do autor do trabalho, de ser um estudioso capaz de avançar na disciplina à qual se dedica; (b) originalidade, no sentido de conhecer profundamente um assunto de forma a "descobrir" algo que não foi dito pelos demais estudiosos. Nessa mesma linha, Castro (2006) afirma que a tese deve contemplar conjuntamente os atributos: originalidade, importância e viabilidade. Martins e Theóphilo (2007) elucidam que a originalidade não se refere às descobertas e às invenções como as próprias das ciências naturais, mas, sim, a apontar um caminho novo, diferente perspectiva, algo que possa representar interesse para os outros estudiosos da área.

A academia estadunidense, segundo Schiehll, Borba e Murcia (2007), considerada mainstream em Contabilidade, tem assumido historicamente conceitos da Economia e sustentada no chamado método positivo, que basicamente contempla: (a) o desenvolvimento de hipóteses; (b) teorias econômicas que sustentam as hipóteses utilizadas; (c) testes empíricos que se valem de técnicas econométricas; (d) conclusões que são capazes de explicar e prever algo que colabore com a construção teórica. Os autores consideram que esse entendimento de pesquisa em Contabilidade deve ser amplamente difundido pelas universidades de elite, como, por exemplo, Chicago, MIT, Rochester, Stanford, etc., e os 
programas de PhDs dessas universidades. A pesquisa também será estimulada e condicionada por journals de prestígio na area, tais como: The Accounting Review (TAR), Journal of Accounting Research (JAR), Journal of Accounting and Economics (JAE), Contemporary Research (CAR) and Review of Accounting Studies (RAS).

\subsection{Estudos Assemelhados}

As pesquisas de natureza epistemológica no campo das Ciências Contábeis no Brasil são relativamente recentes. Riccio et al. (1999) realizaram um levantamento na totalidade das dissertações e teses defendidas entre 1962 e 1999, nos três programas de pós-graduação em Contabilidade existentes à época. Nesse estudo, foram identificados os principais temas abordados, as estratégias de pesquisa e os métodos de coleta e análise de dados utilizados nos referidos estudos.

Theóphilo (2000) realizou uma pesquisa nas teses e dissertações defendidas no Programa de Pós-Graduação em Contabilidade e Controladoria da Faculdade de Economia, Administração e Contabilidade da Universidade de São Paulo, no período de 1984 a 1998. Foi constatada pouca diversidade nos tipos de trabalhos encontrados, os quais tinham sempre os mesmos paradigmas e formatos parecidos. Também foi constatada forte predominância de pesquisas teóricas e bibliográficas e, por conseguinte, raras teses que apresentavam pesquisas empíricas. Além disso, muitos estudos apresentaram problemas quanto à validação dos seus resultados.

Martins (2002) empreendeu uma avaliação do periódico Caderno de Estudos, atual Revista de Contabilidade \& Finanças - USP, publicada pela FEA/USP, no período de 1989 a 2001. Foi verificado que, naquele período - e ainda hoje - são recentes os estudos epistemológicos sobre a produção veiculada em periódicos brasileiros. Corroborando os estudos de Theóphilo (2000), foi constatada baixa proporção de pesquisas empíricas, predominando estudos com enfoque exclusivamente bibliográfico. Boa parte do que era escrito referiase a relatos impressionistas de casos e situações e propostas não seguidas de verificação científica. No entanto, no período compreendido entre 1996 e 2001, fatos positivos foram verificados, como um aumento crescente de citações de periódicos, teses e dissertações.

Posteriormente, Theóphilo (2004) realizou nova pesquisa envolvendo a produção científica em Contabilidade no Brasil. Foram analisados 238 trabalhos, publicados no período de 1994 a 2003, entre teses, dissertações, artigos de periódicos e congressos com as melhores avaliações no sistema Qualis da Capes. Ratificando os resultados de Martins (2002), o autor verificou que os resultados apontavam para uma melhoria geral na qualidade metodológica dos trabalhos. Foi evidenciada uma mudança de ênfase dos trabalhos, de estudos teóricos para estudos teórico-empíricos. No entanto, alguns desafios foram colocados pelo autor: necessidade de maior diversidade de abordagens metodológicas, teóricas e de estratégias de pesquisa; maior rigor metodológico; execução de 


\section{repec}

inventário criterioso do estágio do conhecimento acumulado sobre o assunto estudado; e desenvolvimento de estudos em profundidade, que visem à proposição de ideias a partir de novas visões e perspectivas.

Com um enfoque diferenciado, Martins (2007) analisou os pareceres dos avaliadores dos trabalhos aprovados e apresentados no $5^{\circ}$ Congresso USP de Controladoria e Contabilidade. Devido à expressiva proporção de trabalhos empíricos, foi confirmada novamente a tendência de crescimento dessa abordagem metodológica nos estudos sobre Contabilidade no Brasil. Entretanto, também foi constatado que, em aproximadamente $65 \%$ das menções a pontos fortes, os indicadores da aprovação dos textos se resumiram à relevância do assunto-tema, da redação e da estruturação do trabalho. De modo geral, as avaliações qualitativas dos pareceristas eram lacônicas e telegráficas, tanto quando expressavam pontos fortes dos trabalhos ou quando manifestavam pontos fracos dos textos, apresentando muitos deles inconsistências internas e elevados graus de incompreensibilidade.

Beuren, Schlindwein e Pasqual (2007) investigaram a pesquisa em Controladoria nos trabalhos publicados em anais do EnANPAD e do Congresso USP de Controladoria e Contabilidade, no período de 2001 a 2006. A pesquisa evidenciou os temas abordados, os métodos de pesquisas adotados, as abordagens da controladoria estudadas, a filiação dos pesquisadores e a bibliografia consultada e referenciada nos 439 trabalhos encontrados. Frezatti e Borba (2000) já haviam realizado estudo similar a partir de periódicos internacionais, todavia focados em aspectos ligados às subáreas da Contabilidade, analisando quais temas apresentavam maior foco de cobertura para tais periódicos.

\section{TRAJETÓRIA METODOLÓGICA}

\subsection{População Investigada}

Para execução da análise proposta, foi estabelecido o horizonte temporal de cinco anos, de 2004 a 2008. O estudo abarca todas as teses de doutorado em Ciências Contábeis defendidas na FEA/USP no período de 2004 a 2008. Este recorte, conforme outrora mencionado, leva em consideração apenas a análise do programa de doutorado da USP, desconsiderando os programas que não apresentaram concluintes no período coberto pela pesquisa. Além disso, a divisão em cinco anos é compatível com um estudo realizado por Theóphilo (2004), que compreendeu dois períodos: 1994 a 1998 e 1999 a 2003, representando uma continuidade de igual intervalo de tempo, podendo, assim, serem estabelecidas comparações e avaliação de tendências da produção científica em foco.

Com base nos critérios definidos, apresenta-se, na Tabela 1, a população de teses consideradas neste estudo. 
Tabela 1 - População de estudo: número de teses defendidas no período de 2004 a 2008 em Ciências Contábeis no Brasil

\begin{tabular}{|c|c|c|}
\hline AGENTE DA PRODUÇÃO & ANO & POPULAÇÃO \\
\hline USP & 2004 & 7 \\
\hline USP & 2005 & 17 \\
\hline USP & 2006 & 6 \\
\hline USP & 2007 & 7 \\
\hline USP & 2008 & 13 \\
\hline Total & & $\mathbf{5 0}$ \\
\hline
\end{tabular}

Fonte: Dados obtidos junto à biblioteca da FEA/USP - Organizado pelos autores

\subsection{Procedimentos Metodológicos}

Este é um estudo de natureza predominantemente qualitativa, com enfoque teórico-empírico. Para o alcance dos propósitos almejados, as técnicas de coleta de dados e informações utilizadas nos exames dos trabalhos são: análise documental e análise de conteúdo. De acordo com Gall, Gall e Borg (2003, p. 204), estes métodos fazem parte da modalidade de pesquisa histórica, na em que pesquisas sistemáticas são conduzidas em torno da interpretação de eventos passados. A utilidade de métodos qualitativos, segundo Giangreco e Taylor (2003, p. 133), é idealmente adequada para prover entendimento do contexto e das descrições de como as práticas se manifestam em um ambiente social.

Inicialmente foram baixadas 36 teses em Ciências Contábeis que estavam disponíveis no portal de teses e dissertações da FEA/USP, sendo que as 14 restantes foram consultadas na própria biblioteca da FEA por não estarem disponíveis no formato eletrônico. Estas se referiam aos anos de 2004 e 2005. Foram analisadas as seções: resumo, introdução e metodologia. A análise documental pode ser interpretada como representação de artefatos culturais, uma vez que as teses são reflexos temporais e espaciais, conforme Hodder (2000), que influenciam e são influenciados por diversos agentes da sociedade.

A análise de conteúdo empregada teve como base as categorias que serão descritas na seção 3.3. Segundo Bardin (1997, p. 42), a análise de conteúdos visa "obter, por procedimentos sistemáticos e objetivos de descrição do conteúdo das mensagens, indicadores (quantitativos ou não) que permitam a inferência de conhecimentos relativos às condições de produção/recepção (variáveis inferidas) destas mensagens".

\subsection{Categorias}

As categorias e as respectivas subcategorias estabelecidas a partir da plataforma teórica estão descritas no Quadro 1. A tipologia de estudos, embora tenha suas bases em Castro (2006), foi ajustada seguindo a hierarquia proposta por Theóphilo (2004). Assim, 
consideram-se inicialmente dois tipos de estudos: 'teórico' e ‘teórico-empírico'. Tal procedimento é justificado pelo autor mediante o entendimento de que, em um primeiro estágio, os diversos estudos diferem entre si pelo fato de conterem, ou não, pesquisa empírica.

\section{Quadro 1 - Categorias e subcategorias de análises}

\begin{tabular}{|l|l|}
\hline \multicolumn{1}{|c|}{ Categorias } & \multicolumn{1}{c|}{ Subcategorias } \\
\hline Enunciação do problema de pesquisa & Enunciação do problema. \\
& Problema acessível a um campo do conhecimento. \\
& Elementos relevantes do problema explicitados. \\
& Foco do problema delimitado. \\
& Juízo de valor presente nas questões de pesquisa. \\
& Questões passíveis de respostas do tipo "sim" ou "não"? \\
\hline Tipo de estudo & Revisão de literatura. \\
& Didático. \\
& Proposta de modelo teórico \\
& Teórico-empírico. \\
& Experimento. \\
& Quase-experimento. \\
& Levantamento. \\
& Estudo de caso. \\
& Pesquisa-ação. \\
& Proposta de modelo baseado em pesquisa empírica. \\
& Documental. \\
& Crítico-reflexivo. \\
\hline Tese & Enunciação da hipótese. \\
& Relação de causalidade acidental. \\
& Relação de causalidade necessária. \\
& Relação de causalidade necessária e determinada. \\
\hline Enunciação da tese. \\
& Viabilidade do estudo. \\
& Importância do estudo. \\
& Originalidade do estudo. \\
\hline & \\
&
\end{tabular}

Fonte: adaptado de Theóphilo, 2004.

\section{Análise dos Resultados}

No decorrer da análise dos resultados, foram estabelecidas algumas comparações com o estudo empreendido por Theóphilo (2004). No entanto, cabe destacar que a população investigada não é a mesma. Enquanto o estudo de Theóphilo abarcou teses, dissertações, anais de eventos científicos e periódicos por meio de amostras, esta pesquisa foca, exclusivamente, as teses de doutorado em Ciências Contábeis. 
Antes de iniciar a análise das variáveis, problemas de pesquisa, hipóteses e teses, serão analisados os tipos de pesquisas realizadas. Tal análise se faz necessária a fim de auxiliar no entendimento das demais variáveis.

\subsection{Tipo de Estudo}

Theóphilo (2004) classifica como estudos teóricos aqueles realizados mediante as estratégias de pesquisa: i) revisão de literatura: caracterizam-se esses estudos pela pouca ambição. Em regra, o conteúdo da introdução e da conclusão são os mesmos; ii) estudos didáticos: a pretensão do autor é de ensinar em vez de pesquisar; iii) propostas de modelo teórico: são trabalhos bastante ambiciosos e ocupam-se mais em fazer uma apologia ao modelo proposto do que desenvolver uma discussão criteriosa acerca de suas características e sustentação lógica; e iv) estudos críticos reflexivos: propõem-se a contribuir com uma discussão crítica acerca dos problemas da área, mas muitos deles ficam na simples revisão teórica.

A Tabela 2 apresenta os percentuais de estudos teóricos identificados por esta pesquisa de forma comparativa aos resultados alcançados por Theóphilo (2004).

\section{Tabela 2 - Percentual de Estudos Teóricos Identificados}

\begin{tabular}{|l|c|c|}
\hline \multicolumn{1}{|c|}{ Classificação } & Theóphilo (2004) & Esta Pesquisa \\
\hline Revisões de literatura & $7 \%$ & $2 \%$ \\
\hline Trabalhos didáticos & $6 \%$ & $10 \%$ \\
\hline Propostas de modelos teóricos & $14 \%$ & $4 \%$ \\
\hline Estudos crítico-reflexivos & $16 \%$ & $0 \%$ \\
\hline Totais & $\mathbf{4 3 \%}$ & $\mathbf{1 6 \%}$ \\
\hline
\end{tabular}

Fonte: elaborada pelos autores

Como se verifica, o total de estudos teóricos caiu de $43 \%$ para apenas $16 \%$. Tendo havido as maiores reduções nas modalidades "propostas de modelos teóricos", em 10\%, e "estudos crítico-reflexivos", que eram 16\% anteriormente e neste estudo não apareceram. Como será visto adiante, houve uma migração do tipo teórico para teórico-empírico.

Os estudos classificados como teórico-empíricos são aqueles realizados mediante as estratégias de pesquisa: experimento; quase-experimento; levantamento; estudo de caso; pesquisa-ação; proposta de modelo baseado em pesquisa empírica; e pesquisa documental (THEÓPHILO, 2004). Neste estudo, totalizaram $84 \%$ dos casos analisados e categorizados, conforme apresentado na Tabela 3. 
Tabela 3 - Percentual de Estudos Teóricos Identificados

\begin{tabular}{|l|c|c|}
\hline \multicolumn{1}{|c|}{ Classificação } & Theóphilo (2004) & Esta Pesquisa \\
\hline Experimentos & $0 \%$ & $0 \%$ \\
\hline Quase-experimentos & $5 \%$ & $58 \%$ \\
\hline Levantamentos & $18 \%$ & $8 \%$ \\
\hline Estudos de caso & $13 \%$ & $2 \%$ \\
\hline Pesquisa-ação & $1 \%$ & $0 \%$ \\
\hline Propostas de modelos baseados em pesquisas empíricas & $3 \%$ & $8 \%$ \\
\hline Pesquisas documentais & $17 \%$ & $8 \%$ \\
\hline Totais & $\mathbf{5 7 \%}$ & $\mathbf{8 4 \%}$ \\
\hline
\end{tabular}

Fonte: elaborada pelos autores

Os experimentos são mais comuns nas ciências naturais. Já os quase-experimentos vêm se consolidando de forma crescente, ao longo dos anos, como uma estratégia bastante aplicada na Contabilidade. Theóphilo (2004) havia detectado $5 \%$ da amostra nesta modalidade. Neste estudo, foram evidenciados 29 trabalhos (58\%). Os autores, em geral, testam as hipóteses utilizando bancos de dados (Revista Maiores e Melhores; Bovespa; Economática; Banco Central; etc.) com informações passadas (ex post facto) por meio de ferramentas estatísticas. (THEÓPHILO, 2004). Esta abordagem tem ocorrido predominantemente nos últimos anos.

Essa tendência também tem sido verificada no cenário americano. De acordo com Bouillon e Ravenscroft (2010, p. 26), em termos de metodologia, foi verificado que o aumento nas bases de dados e pacotes estatísticos, tais como Compustat, tornou mais fácil para um estudante de doutoramento fazer uma tese de tipo archival - primary research methodology (a classificação para o mercado com base em estudos empíricos). O percentual de teses usando essa modalidade passou de $21,3 \%$ nos anos 1970 para $53,9 \%$ das teses de doutorado em Ciências Contábeis no período de 2000-2006. Como os novos bancos de dados tornaram-se mais facilmente disponíveis aos estudantes no ensino de graduação, é de se esperar que os doutores tenham tido experiência prévia com tais bancos de dados.

No estudo desenvolvido por Theóphilo (2004), foram encontrados $18 \%$ dos trabaIhos realizados por meio de levantamentos. Esses estudos geralmente utilizam questionários e/ou entrevistas; não aprofundam as análises; geralmente são pouco críticos; e não buscam relações entre variáveis. Na pesquisa presente, foram encontrados apenas quatro desses trabalhos (8\%).

Os estudos de casos constituem uma estratégia que vem sendo menos aplicada. Eram 13\% da amostra de Theóphilo. Nesta investigação, encontrou-se apenas um trabalho (2\%), conforme demonstrado na Tabela 3. Da mesma forma, afirmam Bouillon e Ravenscroft (2010, pp. 25-26) que, durante a década de 1970 e na primeira metade da década de 
1980, os métodos survey e estudos de caso foram as abordagens predominantes nas teses de doutorado em Ciências Contábeis nos Estados Unidos, respondendo por 43,6\% do total de teses. No entanto, esse percentual diminuiu para $14,2 \%$ no final da década de 1990 , tendo tido um ligeiro aumento para $18,3 \%$ a partir de 2000 .

Seguindo a mesma tendência encontrada em Theóphilo (2004), na qual as propostas de modelos baseados em pesquisa empírica representaram apenas $3 \%$ dos trabalhos da amostra, foram identificados apenas quatro trabalhos (8\%) no presente estudo. Esses estudos se utilizam de dados reais para demonstrar a aplicação do modelo, os quais são utilizados como exemplos para sustentar a argumentação sobre sua aplicabilidade.

As pesquisas documentais também foram menos utilizadas no período em análise. Theóphilo (2004) havia identificado $17 \%$ dos trabalhos. Neste estudo, apenas quatro trabaIhos (8\%) utilizaram esta modalidade. Essa seria uma estratégia bastante útil em pesquisas na área, pois a Contabilidade se ocupa da geração e da divulgação de informações por meio de relatórios, demonstrações e outros documentos.

Finalmente, a modalidade pesquisa-ação encontrada em $1 \%$ dos estudos investigados por Theóphilo (2004) não apareceu no escopo deste estudo, muito embora, conforme lembra o autor, são amplas as possibilidades para essa estratégia nas investigações em Contabilidade e Controladoria.

\subsection{Problema de pesquisa}

Pode-se dizer que o problema é o fio condutor da pesquisa científica, dada a sua importância no processo de investigação. Enunciá-lo claramente é o primeiro passo. Nesse sentido, pode-se confirmar a evolução percebida por Theóphilo (2004), pois em sua pesquisa foi constatado que apenas $57 \%$ dos estudos da amostra possuem o problema de pesquisa declarado no período de 1994 a 1998 , tendo este percentual subido para $88 \%$ no período de 1999 a 2003. Neste estudo, constatou-se que todas as teses (100\%) apresentaram os problemas de investigação em forma de questões interrogativas ou as indicaram nos objetivos (8\%), o que é igualmente válido.

Outro aspecto importante na construção do problema de pesquisa se refere às questões de valor, uma vez que questões dessa natureza não são passíveis de verificação, portanto têm sua cientificidade comprometida. Nesse ponto, também se verifica relativa melhoria. Theóphilo (2004) encontrou questões de juízo de valor em $15 \%$ dos trabalhos investigados. No presente estudo, tais questões foram encontradas apenas em quatro trabalhos (8\%), como no exemplo destacado:

É possível obter retornos anormais (...) utilizando-se a análise de demonstrações contábeis para identificação de boas oportunidades de investimentos no mercado de capitais brasileiros? (Trabalho 41). 
Também foram encontrados termos que carregam forte conteúdo valorativo, sem que se observe um cuidado maior nesse sentido como, por exemplo, "(...) avaliar adequadamente a discricionariedade dos gestores" (Trabalho 36). O uso de tais termos indica a ênfase exacerbada nos fins ao invés de nos meios, comprometendo a cientificidade da pesquisa. Outra inadequação na formulação do problema de pesquisa bastante presente nas teses são as questões passíveis de serem respondidas por meio de simples respostas do tipo 'sim' ou 'não'. Theóphilo (2004) registrou 14\% da amostra analisada com esta deficiência. Nesse aspecto, não foram verificados grandes avanços, pois 31 das 50 teses levantadas neste trabalho (62\%) apresentaram questões com respostas do tipo 'sim' ou 'não', muito embora a maioria desses trabalhos questione, de alguma forma, a existência de relações entre variáveis, o que os torna válidos cientificamente. Mesmo assim, ainda permanecem trabalhos com questões que não abordam relações entre variáveis.

\subsection{Hipóteses}

Na pesquisa realizada por Theóphilo (2004), foi constatado que a hipótese não era um elemento muito presente nos trabalhos. Isso ocorria devido ao fato de que poucos trabaIhos buscavam estabelecer relações entre variáveis ou fenômenos. Neste estudo, diferentemente, verifica-se que 31 trabalhos (62\%) enunciaram suas hipóteses. Esta modificação é coerente com a mudança de tipos de estudos ocorridos, nos quais os trabalhos teóricoempíricos saltaram de $57 \%$ em Theóphilo (2004) para $84 \%$ neste estudo, notadamente, a subcategoria "quase-experimento", que saltou de 5\% para $58 \%$.

Se a quantidade de estudos que enunciaram hipóteses aumentou significativamente, o mesmo não se pode dizer sobre as relações de causalidade. Com base em Matallo Júnior (1988), as hipóteses enunciadas foram classificadas em: causalidade acidental, causalidade necessária e causalidade necessária e determinada. Verificou-se que dos 31 trabalhos que enunciaram hipóteses, 19 trabalhos (38\% da amostra) apresentaram hipóteses cuja relação causal era acidental, por exemplo:

Os modelos propostos na literatura corrente para estimar os accruals discricionários utilizados na detecção de gerenciamento de resultados contábeis apresentam validação teórica e empírica para avaliar adequadamente a discricionariedade dos gestores. (Trabalho 36);

Doze trabalhos (24\% da amostra) apresentaram hipóteses com relação de causalidade necessária, por exemplo: "Quanto maior o disclosure, menor o custo do capital próprio" (Trabalho 35). Nenhum trabalho apresentou hipóteses com relação de causalidade necessária e determinada (o que era de se esperar, uma vez que este tipo de hipótese ocorre, normalmente, nas ciências naturais). 


\subsection{Teses}

Esta variável, diferentemente das demais, não encontra parâmetros de comparação em Theóphilo (2004). Nessa perspectiva, mesmo diante de limitações, o presente estudo avança no sentido de contribuir com a cientificidade das pesquisas em Ciências Contábeis.

Avaliar os atributos "viabilidade", "originalidade" e "importância" de uma tese, depois de defendida, é algo bastante subjetivo. Imagina-se que a viabilidade foi alcançada, uma vez que o trabalho foi concluído. Já a originalidade e a importância se apresentam como categorias extremamente difíceis de serem submetidas a testes, principalmente, se se considerarem as especificidades de cada área investigada. É praticamente impossível a um epistemólogo abarcar todas as áreas e subáreas, mesmo se tratando somente das Ciências Contábeis.

No entanto, Martins e Theóphilo (2007) destacam dois sentidos principais de uma tese: i) identificar uma proposição formulada com o intuito de ser defendida em público; ii) designar a publicação que contém uma tese.

Assim, verifica-se, no primeiro aspecto, importante o fato de enunciar claramente a tese a ser defendida. Nesse sentido, constatou-se que nos trabalhos analisados somente dez trabalhos (20\%) enunciaram claramente as teses defendidas. Um percentual extremamente pequeno, uma vez que se trata de pesquisas realizadas em nível de doutorado. Além disso, foi verificado que, nos anos 2004, 2005 e 2006, em nenhum dos trabalhos analisados, foi feita a enunciação da tese defendida. As teses começaram a ser enunciadas somente a partir do ano 2007.

\section{CONCLUSÕES, LIMITAÇÕES E RECOMENDAÇÕES}

A produção científica em Contabilidade no Brasil é relativamente baixa se comparada a outras áreas mais desenvolvidas. Pode-se dizer que é uma área jovem em termos científicos. Assim, é natural que, ao longo dos anos, as pesquisas venham se aprimorando em termos científicos. Essa tendência vem sendo identificada por estudiosos da pesquisa contábil como Martins e Theóphilo (2007), nas últimas décadas. Os resultados deste estudo também corroboram para esse entendimento.

Verificou-se que predominam os estudos teórico-empíricos com ênfase na modalidade 'quase-experimento'. Essa tendência já era identificada em Theóphilo (2004), mas neste estudo constata-se que já é realidade a preferência dos estudiosos por tal abordagem.

A totalidade das teses investigadas enunciou os problemas ou os objetivos de pesquisa. Nota-se redução na quantidade de questões com juízo de valor se comparadas com os estudos de Theóphilo (2004), muito embora permaneça elevada a quantidade de questões com respostas do tipo 'sim' ou 'não'.

Em grande parte dos trabalhos, foi evidenciado o enunciar das hipóteses a serem investigadas. Muito embora a maioria dessas hipóteses verifique relações causais acidentais, 
o que se tem de cientificidade está aquém dos níveis desejados. Também foi constado que alguns autores começaram a enunciar claramente as teses das pesquisas realizadas. Esse fato foi observado somente a partir de 2007.

Como natural limitação de trabalhos qualitativos, Gall, Gall e Borg (2003, pp. 195197) salientam que todas as pesquisas carregam julgamentos subjetivos, e cada indivíduo, cultura e configuração social são únicos, presentes nos documentos analisados e na classificação adotada pelos pesquisadores. Nesse sentido, uma limitação deste estudo se refere à classificação adotada para teses e hipóteses anunciadas. Adotou-se o enunciar da tese como uma afirmação teórica, em acordo com o exposto, por Julia (1969). Poderse-ia ter classificado de forma diferente em alguns casos, principalmente, em pesquisas de natureza empírica. Ao enunciar hipóteses, o autor também estaria enunciando teses preliminares, que, ao final do trabalho, se afirmam ou são negadas quando da realização dos testes empíricos.

Recomenda-se, afinal, a continuidade de estudos epistemológicos nas várias esferas, como dissertações de mestrado, periódicos nacionais e internacionais e comparativos do estágio de pesquisa das Ciências Contábeis no Brasil com a da área em outros países.

\section{REFERÊNCIAS}

ABBAGNANO, N. Dicionário de Filosofia. 5 ed. São Paulo: Martins Fontes, 2007.

BARDIN, Laurence. Análise de conteúdo. Lisboa: Edições 70, 1997.

BEUREN, I. M.; SCHLINDWEIN, A. C.; PASQUAL. D. L. Abordagem de controladoria em trabaIhos publicados no EnANPAD e no Congresso USP de Controladoria e Contabilidade de 2001 a 2006. Revista de Contabilidade e Finanças. São Paulo, v. 18, n. 45, p. 22-37, set/dez. 2007.

BOUILLON, Marvin; RAVENSCROFT, Sue. Undergraduate Preparation and Dissertation Methodologies of Accounting PhDs. over the Past 40 Years. Global Perspectives in Accounting Education, vol. 7, 2010. pp. 19-29.

BUNGE, Mario. "What is science? Does it matter to distinguish it from pseudoscience?" New Ideas in Psychology, vol. 9, n. 2, 1991, pp. 245-283.

CASTRO, Cláudio de Moura. A prática da pesquisa. 2 ed. São Paulo: Pearson Prentice Hall, 2006.

ECO, Umberto. Como se faz uma tese. 15 ed. São Paulo: Atlas, 1992. 
FREZATTI, Fábio; BORBA, José Alonso. Análise dos traços de tendência de uma amostra das revistas científicas da área de contabilidade publicadas na língua inglesa. Caderno de Estudos, v. 13, n. 24, p. 50-78, jul./dez., 2000.

GALL, Meredith. D.; GALL, Joyce. P.; BORG, Walter. R. Educational research: an introduction. 7 ed. Boston: Allyn and Bacon, 2003.

GIANGRECO, Michael F; TAYLOR, Steven J. "Scientific Based Research" and Qualitative Inquiry. Research \& Practice for Persons with Severe Disabilities, vol. 28, n.3, pp.133-137, 2003.

HODDER, I. The interpretation of documents and material culture. In: N. K. Denzin, \& Y. S. Lincoln (Eds.), Handbook of qualitative research. 2 ed. Thousand Oaks, CA: Sage Publications. 2000, pp.703-715.

KERLINGER, Fred. N. Metodologia da Pesquisa em Ciências Sociais. São Paulo: EPU, 2007.

JULIA, Didier. Dicionário da Filosofia. Trad. José Américo da Motta Pessanha. Rio de Janeiro: Larousse do Brasil, 1969.

MARTINS, Gilberto de Andrade e THEÓPHILO, Carlos Renato. Metodologia da Investigação Científica para Ciências Sociais Aplicadas. São Paulo: Ed. Atlas, 2007.

Avaliação das avaliações de textos científicos sobre Contabilidade e Controladoria.

Revista de Educação e Pesquisa em Contabilidade - Repec, Brasília-DF, v. 1, n. 1, p. 1-13, jan/abr. 2007.

Considerações sobre os doze anos do Caderno de Estudos. Revista de Contabilidade e Finanças - USP. Universidade de São Paulo, São Paulo, n. 30, p. 81-88, set/dez 2002.

MATALLO JUNIOR. Heitor. A explicação científica. In: CARVALHO, M.C.(org.). Construindo o saber: metodologia científica - fundamentos e técnicas. 8.ed. São Paulo: Papirus, 1998.

MORA, J. F. Dicionário de Filosofia. 4. ed. São Paulo: Martins Fontes, 2001.

NJOKU, J. C., VAN DER HEIJDEN, B. I. J. M.; INANGA, E. L. Fusion of expertise among accounting faculty: towards an expertise model for academia in accounting. Critical Perspectives on Accounting, n. 21, 2010, pp. 51-62 
PARK, Park, Robert, L. Voodoo Science: The Road from Foolishness to Fraud. New York: Oxford University Press, 2000.

RICCIO, E. L., CARASTAN, J., SAKATA, M. Accounting research in brazilian universities: 1962-1999. Caderno de Estudos FIPECAFI, v. 11, n. 22, p. 35-44, set./dez., 1999.

RUFF, Michael; THIBODEAU, Jay C.; BEDARD, Jean C. A Profession's Response to a Looming Shortage: Closing the Gap in the Supply. Journal of Accountancy. vol. 207, n. 3, pp. 36-40, março, 2009.

RUNES, Dagobert D. The Dictionary of Philosophy. New York: Philosophical Library, 1942.

SCHIEHLL, E.; BORBA, J.A. MURCIA, F.D. Financial Accounting: An epistemological research note. Revista de Contabilidade e Finanças da USP. vol. 18, n. 45, pp. 83 - 90, set./ dez, 2007.

THEÓPHILO, Carlos Renato; IUDÍCIBUS, Sérgio de. Uma Análise Crítico-Epistemológica da Produção Científica em Contabilidade no Brasil. UnB Contábil - UnB, Brasília, vol. 8, no 2, Jul/ Dez, 2005.

. Pesquisa em Contabilidade no Brasil: uma análise crítico epistemológica. Tese (Doutorado em Contabilidade) - Faculdade de Economia, Administração e Contabilidade. São Paulo: Universidade de São Paulo, 2004.

Uma Abordagem Epistemológica da Pesquisa em Contabilidade. Dissertação (Mestrado em Contabilidade) - Faculdade de Economia, Administração e Contabilidade. São Paulo: Universidade de São Paulo, 2000.

VERGARA Sylvia Constant. Projetos e Relatórios de Pesquisa em Administração. São Paulo: Ed. Atlas, 2000. 